\title{
BETEL NUT, MAGIC AND BASEBALL: A CASE STUDY OF PUYUMA TRIBE IN TAIWAN
}

\author{
Junwei Yu
}

\begin{abstract}
Despite considerable research being done on Taiwanese aborigines and baseball, no study has been undertaken on magic and baseball in regard to specific indigenous ethnic groups. This article examines the extent to which betel nuts were used as a vehicle for the expression of human relationships with the supernatural in baseball. The Puyuma, renowned for practicing black magic, have always been accused, in particular, by the Amis, of casting evil spells on the ballpark to achieve their own ends, such as winning. Empirical materials have been drawn from fieldwork in Taidong, where in-depth interviews were conducted with coaches and players from the Amis, Puyuma, Bunun and Han Chinese groups. Additional sporadic secondary sources have also been drawn on. The author argues that in spite of the discovery of betel nuts buried in the ballpark, there is no solid evidence of malicious intent by the Puyuma. Moreover, the betel-nut-spell practice corresponds with the intellectualist perspective that magic has gradually died out, since it contradicts the basic principle of baseball, namely, scientific training.
\end{abstract}

Keywords: Puyuma, baseball, betel nuts, black magic, Amis

\section{INTRODUCTION}

Generally speaking, people do not make connections between betel nuts, magic and baseball. This essay argues that the Puyuma tribe indubitably applies its folk religion to baseball, and produces a unique sports phenomenon. I was intrigued by this topic because of a research trip to Taidong, a place that has the highest percentage and largest group of aborigines in the population, during the winter break in 2010. While on this trip, I talked about the baseball performances of different tribes through casual chats with baseball people there. For example, the Amis, who have whiter skin and tall stature, are born with tremendous athleticism, while the Bunun, Paiwan, and Rukai have darker skin, and have shorter but burlier bodies. As to the Puyuma, they allegedly use magic or witchcraft on the sport fields in a malicious intent towards their 
opponent. It is the mysterious nature of betel-nut-spell practice that triggered my interest in this research.

There are three principle types of theory that explain the occurrence and the functions of magic; these are intellectualist, structural functionalist and psychological. The intellectualist perspective (or evolutionism) suggests that cultural evolution was a universal, linear process from "savagery" to "civilisation", during which magic was merely a transitional stage to religion and, ultimately, to science. Tylor (1871) thought that magic was logical, but based on a false reasoning of the natural world. Frazer (1948) furthered Tylor's theoretical framework by proposing two basic principles in magical thought, one being that like produces like and that an effect resembles its cause, and the other that things formerly in contact continue to act on one another. The structural-functional model is based on the assumption that social institutions are best understood in terms of their functions. Accordingly, Radcliffe-Brown (1948) suggested that the functions of magic and ritual are to support group collaboration and interdependence. The psychological school (or functionalism) is represented by Malinowski (1935), who argued that magic has the value of reducing people's anxiety, thereby enabling them to deal with uncertainties in the environment.

Considerable research has been done on aborigines in Taiwanese baseball, either from the historical (Wang 1994; Gao 1995a, 1995b; Yu 2007a; Yu 2007b; Zhang 2007; Yu \& Bairner 2010) or sociological point of view (Qiu 2003; Qiu 2008; Lin \& Zhu 2009), since the miniscule 2 percent of indigenous populations accounts for over 40 percent of players in the domestic professional league. However, there has not yet been any anthropological study done on folk religion and baseball, concerning specific aboriginal groups. In western scholarship, extensive research has been conducted on superstitions, magic, and rituals associated with professional baseball (Gmelch 1971, 1992) and college baseball (Ciborowski 1997), while Bradley and Gordon (2007, 2010) have explored the supernatural rumours and stories surrounding professional baseball and ballparks. Burger and Lynn (2005) compared the superstitious behaviours of American and Japanese players. In terms of magic, Gmelch suggested "that unlike many forms of primitive magic, baseball magic is usually performed to achieve one's own end and not to block someone else's" (2009: 6) - a statement standing in stark contrast to Puyuma's "black magic".

The author conducted two research trips to Taidong, where the Puyuma aboriginal group used betel nuts on the baseball field, in order to collect empirical data. To understand this cultural phenomenon, the techniques involved ranged from archival research to observations, such as participant observation, through to interviews. In total, the author carried out eleven face-to-face semi-structured interviews, with four coaches, three retired players, three active players, and 
one retired school principal. Moreover, one telephone semi-structured interview was made with an active player. Apart from the retired principal and one active player, who were Han Chinese, the others had aboriginal origin, either from Amis, Puyuma, or Bunun. Each one-on-one interview usually lasted about an hour, and was audio recorded. The author also went to a palakuan (men's meeting hall for the Puyuma tribe), to take part in a traditional ceremony, for which a shaman and his assistant had prepared betel nuts.

\section{BRIEF DESCRIPTION OF TAIWANESE ABORIGINES}

In Taiwan, the word 'aborigines' refers to the earliest groups of people arriving in the island and inhabiting it before the Han Chinese, who systematically started to migrate from mainland China to Taiwan only in the seventeenth century. Although there have been several theories relating to the origin of the Taiwanese indigenous populations, research in the fields of linguistics, archaeology and anthropology in recent years has suggested that their ancestors may have been living on the island for approximately 6,000 years before the arrival of large Chinese settlers. According to classifications available in genetics and linguistics, Taiwanese Aborigines belong to the Austronesian group, which is strongly associated with ethnic groups in the South Pacific islands, such as the Philippines, Malaysia, Indonesia, Madagascar and Oceania, amongst other regions. Some linguists have considered Taiwanese to be the origin of Austronesian languages, which makes these native languages carry great historical significance (Blust 1985; Bellwood 1991).

In the early days, Taiwanese aborigines lived in the "frontier" of the territory of China and were viewed as "non-Han Chinese", who were lower in cultural level and irrational in religion and behaviour. In Chinese recorded documents - dossiers and local chronicles - aborigines in Taiwan were referred to as "East Savages" or "Wild Barbarians" (Eastern Savages). In the Qing Dynasty, they were called "East Barbarians", "Wild Barbarians", "Raw Barbarians", "Semi-subdued Barbarians" or "Cooked Barbarians", according to their "level of civilization assimilated to the Han cultural norms". During the Japanese colonial period, Taiwanese aborigines were referred to as a "Barbarian Group" or "Takasagozoku". After the Chinese restoration, the government generally referred to aborigines as "Shanbao" (the mountain compatriots), divided into "Shandi Shanbao" (mountain aborigines) and "Pingdi Shanbao" (plains aborigines) (Wang 2001). It was not until 1994 that they were officially called aborigines. The Ministry of the Interior lists 14 groups as aboriginal tribes, these being the Amis, Bunun, Paiwan, Tsou, Rukai, Puyuma, Saisiyat, Tao, 
Atayal, Thao, Kavalan, Truku, Sakizaya and Seediq. As of June 2010, the total population of Taiwanese Aborigines is 508,380 (approximately 2.1\% of Taiwan's population), and the bulk of contemporary Taiwanese Aborigines reside either in the cities or in the mountains (Ministry of Interior 2010).

Although according to social culture, all Taiwanese aborigines are classified into Malayo-Polynesian system, there remain huge differences between various tribes. For instance, in terms of governance structure, Tao and Bunun are egalitarian societies, while Rukai and Paiwan apply the caste system, separating people into aristocracy and commoners. In terms of religion, the range is from wizard faith without specific form to polytheism. As for family organisation, this varies from patriarchal and matriarchal to double descent society. These tribes, of which there are more than a dozen, demonstrate a huge variety of socio-cultural phenomena.

Taiwan's aborigines have adapted themselves to the ecological environment of the island whilst retaining their particular socio-cultural systems. Moreover, they have also had to endure outside forces - politically, economically, and religiously - and seek to survive in the gap between the maintenance of tradition and ongoing modern transformation. Generally speaking, the socio-cultural system of the Taiwanese aborigines has undergone four transitional stages. First was the period of traditional tribal life; second - the period of Dutch and Qing rule, in which different cultures began to merge; and third - the 51 years of Japanese colonial rule, which completely incorporated the aborigines into the modern state system for the first time. Lastly, the arrival of the KMT (Chinese Nationalist Party) in 1945 witnessed the introduction of pan-Chinese education and ideology, accompanied by a mass exodus of tribal members from their traditional lands, causing a massive crisis in aboriginal culture.

The Japanese colonial government and the later KMT regime systematically and purposely exercised an assimilationist policy toward aborigines in the areas of language and culture, and also penetrated deeply into the tribes through trading and intermarriage, amongst other activities. This caused a huge evaporation of native languages and tribal identity. For example, ten out of approximately twenty-six languages of the Taiwanese Aborigines (known as Taiwan Austronesian languages) have already disappeared, with five of them being on the verge of disappearance, while many other languages have experienced certain levels of damage (Zeitoun \& Yu 2005). 


\section{THE PUYUMA, BETEL NUT AND MAGIC}

In comparison with the population as a whole, Puyuma is a small tribe with approximately ten thousand people. Their habitat covers the eastern side of the Central Mountains, the coastal area of the southern part of the Puyuma River, and the mountain area of the southern East Rift Valley. Puyuma are a very doughty people, whose major inhabitation is in Taidong County. During the Qing Dynasty, they formed eight communities, and made glorious history in the 17th century. In Kangxi and Qianlong period, Beinan, the principal tribe of Puyuma, defeated the remnants of the Zhu Yigui and Lin Shuangwen rebels, respectively. Their chief was granted the court dress and bestowed the title of "The Great Lord Puyuma" (Historical Records 1963; Song 1998). The Puyuma people possessed strong military prowess because all males would undertake a training system known as palakuan.

Puyuma is a matrilineal society that applies uxorilocal marriage. However, this tradition has inevitably had to adjust with the passage of time. To take marriage as an example, now most of them follow the patriarchal principle that women marry into men's families, and children take their father's last name, while in some families half of the children take the mother's name (Song 1998; Temporary Committee 2000). In Puyuma society, there are two key leading persons - one is a male priest, who takes charge of major tribal rites; the other is the political head, a role that is often taken by someone with strong leadership ability in the tribe, who is able to take the responsibility as the mediator of major tribal affairs, and as the leader of hunting, rites and battles. Nowadays, the male priest still remains in his traditional job, and is respected by the tribe, but the position of the political head is different, and can be affected by interference from the modern governmental system (Song 1965; Wei 1965).

The most famous cultural figure is that of the Puyuma shaman, known as bulingow in Zhiben dialect, and tamaramau in the Nanwang tribe. All the neighbouring aborigines are fearful of their magic power, since they are renowned for witchcraft. The shamans - a position usually held by women - have the ability to divine, cast spells and dominate rites, while the wizards often work as bamboo divinators, something that might have been learned from the Amis. Witches and wizards hold an esteemed position in society, so it has become a custom for specific Puyuma women to learn witchcraft in early days, and go through the ordinary procedures of magic learning. A shaman performs a wide range of functions, mainly in regard to healing the sick, dispelling evil spirits and praying for blessings, but also assisting people in searching for lost property and livestock, and dispelling misfortune or calling the spirits (Cauquelin 2004). 
Nowadays, the tribe still preserves their traditional shaman for helping with illnesses, dispelling evil spirits and executing the customs and ceremonies of significant life events. It should be noted that magic further divides into white magic and black magic. The former focuses on healing the sick in order to drive out the misfortune, while the latter, rarely exercised unless necessary, is used to cast spells upon people for evil intentions (Tian 2002).

The betel nut is famously known as a key medium and sacrifice of Puyuma witchcraft and various rites. Without it, people would have lost the means to communicate with the ancestral spirits. The term palisian means "casting a spell or performing rites", which is called salisin by the Amis. ${ }^{1}$ In the early days, when people confronted unfair matters and had no strict laws to follow, the function of casting spells came into existence. In particular, during the time when battles often occurred between tribes, Puyuma witchcraft worked as a means of putting evil spells on the enemy and counteracting or diminishing the opponent's magic power. This function was popular once in the past. Now, only the aged shamans possess this mysterious skill, and it is rare for people to perform such black magic. There are two ways to explain the symbol and function of a betel nut. First, an intact betel nut without any cutting represents the fact that the ancestral spirits have not yet been requested. Second, three betel nuts split open with string-tied pottery beads, or with iron slices inserted into it, represent the fact that the ancestral spirits have already been requested. The Puyuma take the shape of the betel nut to symbolise a person, with the stalk tip as the human head and the fruit as the human body. They cast a spell upon part of the target person, and the power of the spell will be enhanced if the betel nut is inserted with pottery beads or iron slices (Zeng 2009; Baisu 2010).

As to the Amis society, the largest aboriginal group in Taidong, they also have their magic practices. The term kawas refers to all the spirits of heaven and earth and also the deities, souls, ghosts and demons. Many tribes would ask for guidance from kawas through cikawasay (wizards), who may use methods as varied as dreams, bird divination or 'edaw (bamboo divination). The wizards perform 'edaw by stepping on the middle of a slim bamboo branch and dragging both ends of it. They can tell the fortune according to the shape of the cracking gap. The Amis enquire into matters through bamboo divination, and then follow the divining result to dispel evil spirits, heal illness or resolve confusion. However, the Amis practise the ritual for their own benefit, rather than for harmful intention (Yang 2003; Lin 2005). 


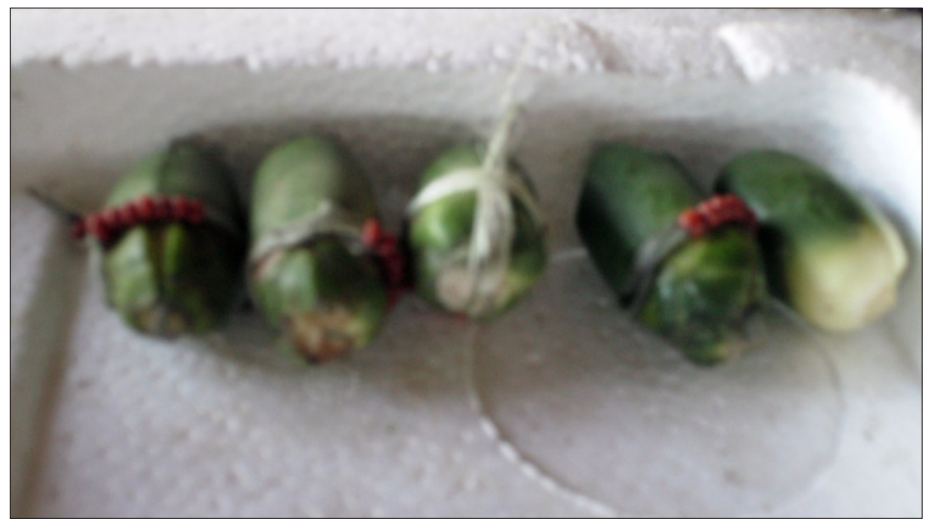

Figure 1. Each betel nut represents an evil spirit. From right to left as follows: natural death, unnatural death, bad thing, gossip, and jealousy. Photo by the author 2010.

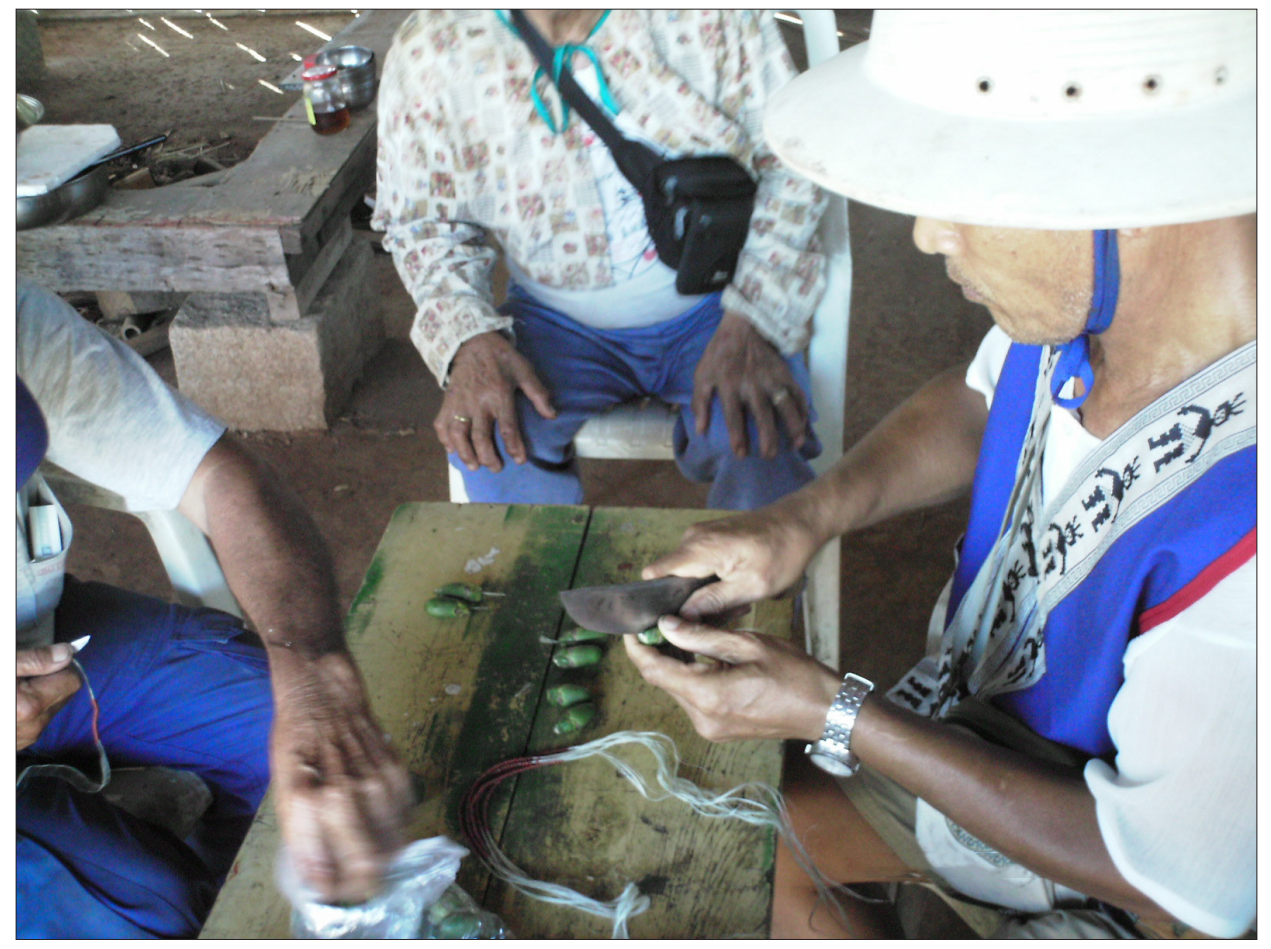

Figure 2. A wizard and his assistant are making a betel nut spell in the palakuan. Photo by the author 2010. 


\section{HONGYE BASEBALL TEAM - VICTIMS OF PUYUMA WITCHCRAFT?}

The aborigines' connection with baseball dates back to the Japanese colonial period, during which the first all-Amis baseball team was formed in 1921, in an attempt to divert their violent barbarism into civilised sport (Xie \& Xie 2003; Yu \& Zeng 2004; Yu et al. 2006). This was followed by the famous Jianong baseball team, comprising several key indigenous players, who took the team to runner-up status in the 1931 Koshien finals held in Japan (Zeng 2001; Lin \& Lin 2005). After the KMT came to Taiwan, Taidong's baseball continued to thrive under the tutelage of Jianong alumni, most of whom were Amis, coupled with a few Puyuma. This is the major reason why currently the Amis constitute such a high percentage in Taiwanese baseball, whether professional or at the grassroots level. Despite a long and rich history of baseball involvement, the importance of folk religion, such as Puyuma's betel nut spell, which might have been applied on baseball, is largely ignored in Taiwan's scholarship.

The book edited by Zhang Jingguo (1983) might be the first print media that recorded baseball and witchcraft. Strangely, however, the specific article that featured the controversial incident did not have any author, thus making it hard to trace the origin. It mentioned the legendary stories of Hongye Little League, who won against Japan Kansai all-star team in 1968. The public dubbed Hongye players as kids who practiced "with wooden sticks as bats and rocks as balls", which touched every person in the island. They lived in such a Cinderella tale that some even claimed that Hongye was the starting point of Taiwanese baseball. However, in the story the author was more intrigued by their altercation over black magic with the Puyuma.

The scene was set in the Hongye village inhabited by the Bunun, with the Puyuma being down from this village. Before the KMT came to Taiwan, the two tribes had their own territory, and had many battles, in which they demonstrated serious hatred against each other. They even had the custom of hunting the opponent's head (Kasahara 2009). It was not until Puyuma chief Ma Zhili successfully brokered a truce between his people and the Bunun in 1939 that the two centuries of mutual killings ended. Though there was still a grudge, after generations under the suppression of Japanese rule, the two tribes had a more forgiving attitude, and are no longer engaged in hostilities as was the case with their ancestors (Sun 2001).

Lin Zhupeng worked as Director of Teaching Affairs in Beinan Elementary School, dominated by Puyuma kids, for ten years before becoming Principal of Hongye Elementary School. He started a baseball team in Hongye to attract students to school, and at the same time, prevent them from truancy. Lin then 
brought the children down from the mountains to play friendly games with Beinan in 1963. However, many Hongye kids started to have diarrhoea. Parents were concerned that the suspected cause was the evil spell from the Puyuma during ball games. As a result, parents disallowed their children from playing baseball and going down for the competition. This placed Principal Lin in a difficult situation, though he tried his best to explain to parents that in this modern time with advanced scientific knowledge, witchcraft or spells were not real. Unfortunately, the Hongye villagers did not take Lin's advice, and training was suspended in less than two months after the team was formed.

To find out the real cause of the problem, Principal Lin invited Cai Wenshui, the chief doctor from the health station of Yenping Township, to do a health check for all the team members. The result showed that diarrhoea was caused by the roundworm and hookworm. He not only asked Cai to help to provide medicine to the students immediately, but also bought flour to make buns, whilst offering nutriments to them. Due to his hard work, the students gradually recovered from the illness and became healthy. Parents would not cast doubt on the mysterious power. Ultimately, with everyone's approval, the team resumed training, and all the players were vigorous. Because of this event, the Bunun and the Puyuma finally erased their grudge, and the Hongye team began its period of glory.

This story is the only written record of baseball and witchcraft. Though no betel nut was mentioned in terms of performing black magic, it vividly demonstrated how fearful the Bunun were towards the Puyuma, especially when bad things occurred. When asked about this event, Lin replied:

They were suspicious of their plot, but I strongly insisted that it was not witchcraft. If they really did want to cast a spell, why not cast it on me, the principal. If I were gone, Hongye could not have continued anymore. It was only because of the roundworms. (Personal communication, August 14, 2010)

As a result, students were sent to a Puyuma doctor, who the parents thought of as being from the evil party, to have a comprehensive health check, and they quickly recovered. Although the reporter claimed that team training was halted due to witchcraft, this was not true. The team carried on their training schedule without being affected by the incident. It is assumed that the journalist dramatically exaggerated this event to achieve higher sales.

According to Hu Meiyun, a first generation Hongye player, "the Bunun and Puyuma indeed had some conflicts over the occupied territory, and both peoples had the custom of hunting each other's heads". As to casting a spell on the Hongye baseball team, he stated: 
I have not heard about it. I think it was because of the poor sanitary conditions at that time; so many people got an infection which caused either illness or diarrhoea. It happened when we lost to Beinan, so parents started to blame it on witchcraft. It was a coincidence. (Personal communication, August 9, 2010)

However, Hu also agreed with the viewpoint of other tribes that Puyuma witchcraft was famous, and, therefore, if he saw betel nuts on his way, he dared not pick them up, and made a detour instead.

\section{PERSONAL EXPERIENCES WITH BETEL NUT AND BASEBALL BEFORE 1972}

In interviewing the Amis coaches, the author found that they unanimously agreed upon the wicked, yet unbelievable, magic power of betel nuts in their childhood. As Guo Zixiong, a retired Amis coach, remembers:

They love to use betel nuts with beads inserted, and then put them there... I don't really understand, I saw a lot of this in my childhood and on the curbs of roads. It was strange, and we were afraid. We did not dare to walk over the nuts; instead, we took a bypass. (Personal communication, February 2, 2010)

A senior baseball player, Gao Kewu, also said, "We were very naïve when we were small, and always thought if people were sick, we should go for a Puyuma witch for healing them" (personal communication, August 9, 2010). This is the typical stereotype of Puyuma witchcraft projected by the Amis people.

A former baseball player, Chen Mingtian, also had unforgettable experience about witchcraft in baseball:

I was playing baseball barefoot in my elementary school time. I made a hit and ran across the bases but sprained [my foot] because of the poor field. My big toe swelled badly, even if I applied ginger on it or a hot compress. Till the third day, I was so much in pain that my mother went for a relative, a Puyuma witch. She started her witchcraft by setting six fresh betel nuts on the ground and began her incantation. She walked into the river, and when walking back, she was breathless and sweating badly. Suddenly, a thing dropped - a dried flat betel nut with beads and a needle in it. It was because she had fought with the evil figure setting up the poisonous spell and finally she defeated it. The next day, my 
swollen toe was cured without taking any pill. (Personal communication, February 3, 2010)

As for the baseball games themselves, it was not until the late 1960s that betel nuts were found in the field. In the 1960s and 1970s, Beinan and Xinsheng Junior High Schools were in close proximity to each other, and in fierce rivalry for district supremacy. The former is located in Beinan area, and therefore had more Puyuma players; the latter is located in Taidong City and had more Amis players. ${ }^{2}$ Chen Mingtian, a former player from Beinan Junior High School, recalled one curious incident:

Our coach asked us to clean up the field before next day's competition. When we took off the home plate to draw lines, we saw betel nuts, about four or five; they were fresh, not dry at all. We stripped the nuts and found three beads and a needle inside. Also, we found more betel nuts under the pitcher's mound. Damn it! Some of the aborigines said this was salisin. They started cursing and threw the betel nuts into the bush without telling the coach and others, to make them believe the betel nuts were still in the field. Because our opponent was Xinsheng Junior High School and the field was so close to them. Moreover, their coach's wife was a Puyuma, so we assumed that they were the culprits for putting the betel nuts there. (Personal communication, February 3, 2010)

However, Wang Jincheng, the coach of the Xinsheng team, provided conflicting statements as to who was responsible for burying betel nuts. He mentioned that every time when they played with Beinan Junior High School, whose Puyuma players accounted for higher percentage, especially in important competitions, they found betel nuts. Therefore, Xinsheng players always arrived on the field thirty minutes earlier, with the purpose of cleaning the field, but in reality they were going to dig out all the betel nuts that might have been buried there. They did this because the parents of players told them to avoid injury (personal communication, August 13, 2010). In their view, the betel nuts represented evil intentions towards people. As distinct from other respondents, who only saw this for a few times, coach Wang had seen this all the way from junior high to senior high in his playing career, especially in regional competitions that involved Puyuma players or coaches in the opponent team.

The Amis player, Yang Jieren, recalled that when they participated in the Taidong Little League Competition in 1972, they lost the game to a team including several Puyuma players. Parents said the match was cursed and later took off the bases to see if there was foul play. Indeed, they found betel nuts under every base (first base, second base, third base, and home plate) as well as the pitcher's mound. At that time, the bases were not located permanently 
on the ground but only fixed by two nails. ${ }^{3}$ People who buried betel nuts must have spent time pulling out the nails and then digging holes to put the nuts in. Since they found the betel nuts after the game, the nuts were all dried out and had beads strung with a thread inside. At the time, Yang and his teammates really believed that they had lost the game because of black magic, and cried out loudly (personal communication, August 12, 2010).

\section{BEINAN JUNIOR HIGH SCHOOL BASEBALL TEAM IN 1994}

The betel nut spell seemed to vanish from 1972 to 1994 . One major reason is the player exodus, due to which many Taidong players went out to play for other cities or counties, thus leading to the dissolution of local teams. As long as there was no team playing in Taidong, the betel nut spell would not appear. But in 1990, the CPBL (Chinese Professional Baseball League) was established, offering a future for grassroots players. At the same time, the Ministry of Education launched the student baseball league, in which players were not allowed to play for the city or county other than their hometown. In addition, Nanwang Elementary School won the champion of Chinese Cup Youth Baseball Tournament, and all the graduates attended Beinan Junior High School. Puyuma coaches, Chen Zhixiong and Chen Fubin, from Nanwan, were hired to provide coherent training for the players. In 1994, these Taidong players finally bore fruit in the National PONY (Protect Our Nation's Youths, aged 13-14) League Qualifying Tournament, in which Beinan and Xinsheng Junior High Schools won the champion and the second place respectively, becoming the first national team in middle school level to come from Taidong since 1945. Beinan represented Taiwan to win the PONY Asia-Pacific Qualifying Championship, and subsequently went on clinching the PONY World Series in Washington, Pennsylvania, in the United States.

Competitions between the two Taidong teams of Beinan and Xinsheng Junior High Schools were often tense, to say the least. As such, both sides called for help from mysterious powers, which was a unique phenomenon. Xinsheng had Amis players from the coastal area, who had better stature. They were viewed as the superior team, especially since they had the tall, six-foot Amis pitcher Chen Yuanjia. Beinan's players were mostly from the mountains; their stature was not as good as that of the Xinsheng players. However, they were also welltrained. In May 1994, Xinsheng clinched the championship, while Beinan only attained third place in the National Under-15 Rubber Baseball Tournament. But the most important competition was the PONY League Qualifying Tournament held in Taichung, where a double-elimination system was used. Xinsheng were 
seen as the favourites to win the competition; surprisingly, they lost to Beinan in the first game. As a result, they went for a repechage, and had to fight their way back, beating the opponents one by one until they ultimately met Beinan in the finals. Xinsheng's parents started to question whether the curse was the cause of their failure, particularly when they saw a Puyuma witch on the stand. As Guo Zixiong, the coach of Beinan, recalled:

As soon as Xinsheng lost [the first match], they started to blame on the spell from Puyuma. The Xinsheng coach's wife was from Nanwan, Puyuma, so he insisted there was mysterious power involved. [In the final], the first base referee asked why the aborigines had brought two god statues on the spectator stand. I was also shocked by seeing this. Those statues of Taoist gods were brought by parents from Xinsheng to counteract the Puyuma witchcraft. After the game finished, I went to the entrance asking those parents why they had brought this stuff to the field. It did not make sense! Later, back in Taidong, I asked them again why they had brought two god statues, for what? For worshipping their gods on the field or for some spiritual ceremony? They replied it was all because the Puyuma people loved using salisin. I burst out laughing ... I told them it was their tradition, but not mine. I told them that they needed to bring a god who could play baseball. The gods they had brought along did not know about baseball, so how could they win the game (laughing wildly). (Personal communication, February 2, 2010)

From the above passage, we can see the transformation of worship beliefs among the Amis, who changed from animism to Taoism as a consequence of rapid Han Chinese assimilation. Most people in the Malan tribe, one of the biggest Amis gatherings in Taidong, had converted to Taoism. Not surprisingly, several Xinsheng parents were willing to bring the prosperity-dispersing Queen Mother of the West (Xi Wangmu) to suppress Puyuma witchcraft, which had become a common topic of chitchat among the locals. ${ }^{4}$ Lu Guanchang, a Xinsheng player, recalled that the Goddess was placed on a deity table, from which incense worship started at the entrance of the dugout facing the opponent team, and was later moved to the stand. He jokingly said that the statue arrived a bit late for the game. Therefore she could not perform the mighty power from the very beginning, and they lost the game to Beinan 0-7 (personal communication, August 28, 2010).

The Queen of the West-versus-Puyuma witchcraft showdown created a hangover that lingered for over a year. ${ }^{5}$ Parents from both sides made accusations against each other, even to the level of committing sacrilege to the opponent's gods. This event was also in the newspapers and later hindered an organised 
effort to form a Taidong all-star team for the IBAF (International Baseball Federation) Under-16 Tournament in 1995. ${ }^{6}$ Neither side would make a concession to the other; therefore, the County Government came out to mediate in order to merge both sides into a dream team, which clinched the national championship later on. Ironically, players from both sides graduated one year later, and entered the same high school, Taidong Sports High School. The grudge between them gradually diminished.

During the PONY Asia-Pacific Qualifying Championship in Japan and PONY World Series in the United States, both Puyuma coaches brought betel nuts on their trips overseas. Officially, a betel nut cannot be carried abroad. It appears that the coaches paid lip services to the regulations. They divided the nuts into five parts and let students carry them separately, thus passing the customs inspection. "We were afraid when inserting those betel nuts into our luggage, for in the States, they had police dogs to smell and search for the contraband. Luckily, we passed all examinations", Gao Wei remembered (personal communication, August 3, 2010). It appears that betel nuts were not only something to be chewed, but could also be used for ball games. Before the team took off, all the betel nuts were sent to the witches, who cast spells upon them so as to endow them with magic powers, which enabled them to function in Japan and the United States.

The Amis coach, Guo Zixiong, did not believe in the magic power of betel nuts as being able to contribute to the performance of the team. But he was deeply convinced that the Puyuma coaches in the same team continued resorting to the enchanted betel nuts, carrying them to America, and burying the objects in the ballpark:

I was joking to the Puyuma coach asking if their god would travel with us all the way to the States. He answered he had already called back home to ask the witch and confirmed that to do so the magic power would still work. I could have set my face against this, but I chose to respect them. I just said it was good to have help even from gods. When they buried those betel nuts, those Americans certainly didn't know what they were doing. They pretended as if they were practicing but actually let students and pitchers go digging holes to put the nuts in. You just put them there, and who would know. So the magic power seemed to go with us to the States and help Beinan win the World Series. (Personal communication, February 2, 2010)

Although the Amis coach asserted that Puyuma coaches did execute the mysterious spell by burying betel nuts under the pitcher's mound and batter's box, this was denied by Beinan pitchers Gao Wei and Luo Jianming. They said their 


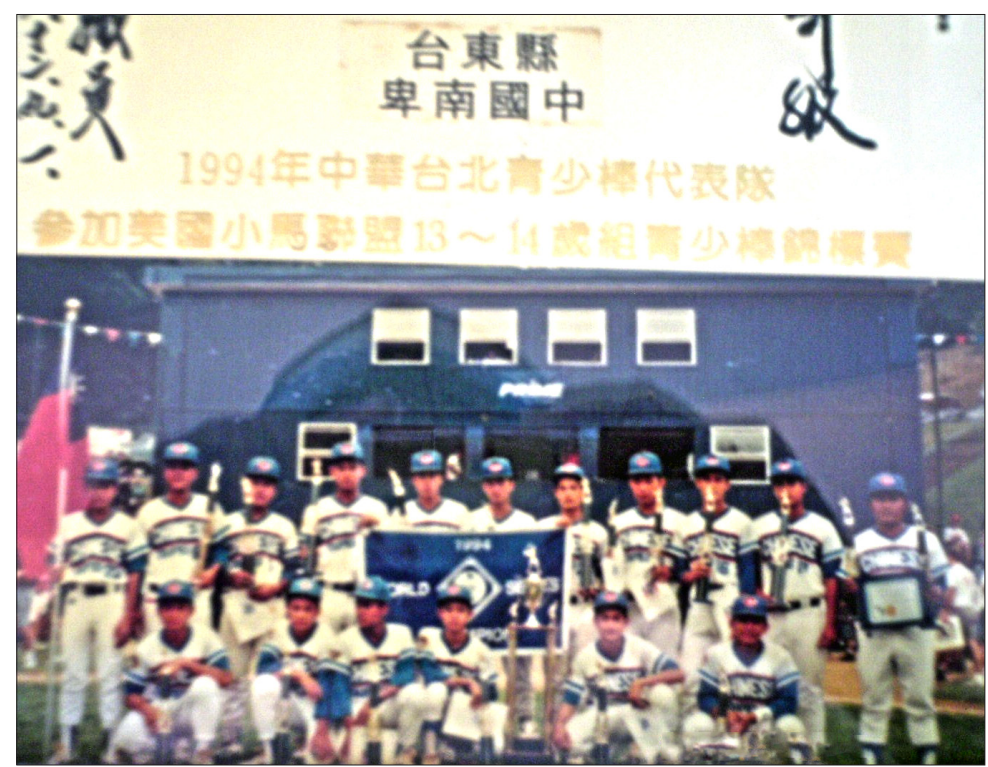

Figure 3. Beinan Junior High School won the 1994 PONY World Series in Washington, Pennsylvania, United States. Photo by the author 2010.

coaches did bring betel nuts to the States, but they buried them outside of the dugout to let players walk across, merely for good luck. They did this to pray in a positive way, but not for cursing or calling up evil spirits. So it might have been because the Amis coach was over-educated about the Puyuma witchcraft, and had a stereotypical view of the Puyuma, who must have won the game by means of the spell. It may be that the Puyuma coaches did secretly set up the betel nuts spell, but this was never discovered by others.

\section{COACHES AND PLAYERS' RESPONSE TO MAGIC}

Recently, betel nut spells have been rarely mentioned, and young players do not find them buried in the field. However, betel nuts can still be used as a medium to pray for good luck. Tian Zhijia, a Puyuma player once playing for Zhongdao High School, mentioned that their head coach was also a Puyuma. Therefore, there was always a dried betel nut attached to their team flag. If the game was tight, especially when the team fell behind in the 7th inning, the head coach would start to mumble aboriginal spells toward the flag. 
He looked so serious that no one dared to bother him. Not a single person had the slightest idea of what he was mumbling about, but strangely enough, the game would end up with a draw, and sometimes a win! (Personal communication, August 4, 2010)

An interesting thing was that the ten-year Zhongdao team was often knocked out during the early group stage in virtually every national competition, despite calling for blessings from "ancestral spirits".

All the Amis coaches, both in the past and nowadays, refute the effect of betel nuts, and regard this as nonsense that has no scientific backing. Due to repeated inculcation of dreadful Puyuma witchcraft by their forefathers, most Amis think that burying betel nuts must be evil, with the negative intention of making the opponent injured or not able to hit well, instead of the common practice of praying for good luck. During the 1960s and 1970s, the Malan Baseball Team composed of only Amis players had its own fixed rite before setting off for the game. The male elder started the rite by reading the Amis curse to call up their ancestral spirits to help their offspring be safe in the game. Then, he would hold rice wine inside his mouth and spray it on the players and the baseball equipment. This rite is performed to pray for blessing rather than evil intention. Other than this, there was bamboo divination. An Amis elder would step on the middle of a slim bamboo branch and drag both ends of it so that he could tell the team's future performance, according to the shape of the cracking gap. Ironically, the retired Malan player Chen Mingtian did not believe in his own people's bamboo divination, but thought the Puyuma rite to be more effective.

Yang Jieren recalls that betel nuts actually had no power over the result of the games. "If they had, the games would not have gone so smoothly, and besides, no players were hurt during the game" (personal communication, August 12, 2010). But they were really upset about losing the vital game, crying so badly and really thinking the betel nuts messed up the match outcome. Chen Mingtian also remembered that "Beinan and Xinsheng both had their winning and losing time, but no one was hurt, so nothing was really influenced by magic. Losing is losing; no one threw the game away deliberately" (personal communication, February 3, 2010). Meanwhile, Wang Jincheng dismissed the Puyuma witchcraft with contempt, saying that "though the magic may only succeed once in ten times, everyone would remember the successful one" (personal communication, August 13, 2010). Even the 18-year-old Puyuma player Chen Zhenghao made a similar statement while playing for Nanwang youth baseball team:

The witch would talk to us first in Mandarin, which was very fluent. She said the ancestral spirit of Beinan would bless and protect us in our 
baseball games. Then she asked us to walk to an open ground, and placed some sand on the grass, and put betel nuts on it. Three nuts on one side, so both sides together had six. She also inserted beads into them. Then she made us stand in front of the nuts and spoke to us. However, we still lost games. I think that rite was only for mental calmness, nothing more. (Personal communication, February 5, 2010)

In interviewing coaches and players, I discovered that the Han people did not really believe or know about Puyuma witchcraft. Like Lin Zhupeng and Fu Qingshun, the key figures for promoting school baseball of Taidong and the former school principals, did not know it at all. Guo Guicai, the coach and a Taoism follower, did not believe it, either. After all, the Han people have little connection with the Puyuma, so they display little wariness of witchcraft when compared to other aboriginal groups. A parent from Puyuma indicated that even in the modern age, the neighbouring tribes of Paiwan and Rukai people are still hesitant about making friends with them, owing to this historical reason.

However, until today, no Puyuma coaches would admit burying betel nuts, either because using black magic was nothing to be proud of, or it was not the coaches who pulled such a stunt. Some people think it was the victory-obsessed parents who may have had recourse to the nuts. In fact, winning a baseball game is based on science and training. If a coach did something against this principle, it would certainly backfire once the results did not go their way. As a Puyuma coach said, "If witchcraft does have such a powerful effect, then players don't have to practice anymore; all they need is burying betel nuts for the results".

Moreover, the lower the education that people receive, the more they tend to believe in magic. Taiwan did not adopt nine-year compulsory education system until 1968; therefore most aboriginal parents only received elementary school education when the betel nut incident occurred. Their eagerness for national champions that brought fame and prospects of playing abroad was very strong, considering the poor and marginalised state of Taidong County. On the contrary, people with a higher educational background are inclined to see magic as a baseless pseudo-science, which has no place in baseball. For instance, the legendary Puyuma player Chen Gengyuan educated during Japanese colonialism was never heard approving this kind of cultural practice. One thing for sure is that Puyuma coaches would invite a wizard or a witch to be a spiritual leader wearing aborigines' traditional outfit and praying for the team. Nevertheless, this kind of practice has also diminished dramatically. 


\section{CONCLUSION}

To Puyuma people, the betel nut is a seed that creates a chewing tobacco-like buzz, but also a tool of worship in their traditional rites. It is more important than rice wine because it acts as a medium that communicates with ancestors and gods. This article has sought to analyse the symbolic meaning and cultural practice of betel nut spell on baseball from the viewpoint of cultural anthropology, through empirical data collected within fieldwork and existing secondary materials. For historical reasons, different groups of people have different interpretations of cultural symbols. For example, all Amis think that the burial of betel nuts is motivated by malicious intentions, instead of good blessings. In addition, they assert that betel nuts must come with Puyuma people, who cast evil spells secretly. In contrast, the Puyuma only admit that the betel nut is used for benign praying, as well as for chewing, thus totally denying the evil intention that lies behind the use of the nut. It is more likely that Puyuma parents buried it secretly, with coaches giving silent consent. When their opponent found the betel nuts, they tended to blame the Beinan coaches.

Returning to the three theoretical approaches suggested earlier, the practice of Puyuma betel nuts matches the intellectualist approach, which emphasises that magic would eventually be replaced by science. Indeed, as the government gradually opened up educational opportunities to the masses, no betel nuts have been seen buried in the field since 1994. After all, performances of baseball players are based on scientific training, while witchcraft is viewed as superstitious, without any scientific support. If anyone wants to tamper with this principle through the use of magic power, they may well be ridiculed by others and exert a negative influence on the team. Although functionalists claimed that magic can engender the sense of confidence, competence, and control of players and coaches in achieving the desired results, and the structural-functionalists suggested that magic can help define Puyuma identity and consolidate tribal culture, it seems that coaches and players, be they Puyuma, Amis or Bunun, do not see the betel nut spell as providing such functions. However, the practice certainly reinforces the negative stereotypes held by other aboriginal tribes towards the Puyuma.

\section{ACKNOWLEDGEMENTS}

This study is supported by the grant from National Science Council (101-2410H-028-002). 


\section{NOTES}

1 To Amis society, salisin means the general worship of gods and ancestry, but the term transforms into black magic when referring to Puyuma's betel nuts.

2 Although Beinan Junior High School had a higher Puyuma percentage compared to Xinsheng Junior High School, the Amis still constituted the majority of the team.

3 The Hollywood style base, which is tough, durable and convenient to handle, has now been accepted for baseball grounds throughout the country, instead of primitive form bases fixed by nails.

4 The earliest possible reference to the Queen Mother of the West occurs in the Chinese Shang dynasty, after which she evolved from being immortal to being one of the major deities of Taoism.

5 Most Amis players and coaches mistakenly identified the deity that the Xinsheng parents brought as the demon-killing Third Prince of Jade Emperor, but it was actually the Queen Mother of the West.

6 The author recalls seeing the grudge between Beinan and Xinsheng's parents in certain newspapers, but unfortunately could not retrieve the article.

\section{MANUSCRIPT SOURCES}

Interviews and fieldnotes from Taidong County (2010) in the possession of the author.

\section{REFERENCES}

Baisu, Lixin 2010. Yuanzhumin zazhi: 'edaw zhuzhan. [News and Magazine of Aborigines: 'Edaw Bamboo Divination.] Taiwan Lihpao. Available at http://www.lihpao. com/?action-viewnews-itemid-5866, last accessed on April 18, 2013.

Bellwood, Peter 1991. The Austronesian Dispersal and the Origins of Languages. Scientific American, Vol. 265, No.1, pp. 88-93, doi:10.1038/scientificamerican0791-88.

Blust, Robert 1985. The Austronesian Homeland: A Linguistic Perspective. Asian Perspective, Vol. 26, No. 1, pp. 45-67.

Bradley, Mickey \& Gordon, Dan 2007. Haunted Baseball: Ghosts, Curses, Legends, and Eerie Events. Guilford, Conn.: Lyons Press.

Bradley, Mickey \& Gordon, Dan 2010. Field of Screams: Haunted Tales from the Baseball Diamond, the Locker Room, and Beyond. Guilford, Conn.: Lyons Press.

Burger, Jerry M. \& Lynn, Amy L. 2005. Superstitious Behavior Among American and Japanese Professional Baseball Players. Basic and Applied Social Psychology, Vol. 27, No. 1, pp. 71-76, http://dx.doi.org/10.1207/s15324834basp2701_7.

Cauquelin, Josiane 2004. The Aborigines of Taiwan. The Puyuma: From Headhunting to the Modern World. London \& New York: RoutledgeCurzon. 
Ciborowski, Tom 1997. "Superstition" in the Collegiate Baseball Player. The Sport Psychologist, Vol. 11, No. 3, pp. 305-317.

Frazer, James George 1948. The Golden Bough: A Study in Magic and Religion. Abridged edition. New York: Macmillan.

Gao, Zhengyuan 1995a. Yuanzhu min yu taiwan bangyun (1). [Aborigines and Taiwanese Baseball (1).] Shanhai wenhua shuang yuekan [Taiwan Indigenous Voice Bimonthly], Vol. 9, pp. 32-36.

Gao, Zhengyuan 1995b. Yuanzhu min yu taiwan bangyun (2) [Aborigines and Taiwanese Baseball (2).] Shanhai wenhua shuang yuekan [Taiwan Indigenous Voice Bimonthly], Vol. 10, pp. 26-30.

Gmelch, George 1971. Baseball Magic. Society, Vol. 8, No. 8, pp. 39-41, http://dx.doi. org/10.1007/BF02908325.

Gmelch, George 1992. Superstition and Ritual in American Baseball. Elysian Fields Quarterly, Vol. 11, No. 3, pp. 25-36.

Gmelch, George 2009. Baseball magic. Sociology 101. Available at http://sociology101. net/readings/Baseball-Magic.pdf, last accessed on April 18, 2013.

Historical Records 1963 = Historical Records Committee of Taidong County 1963. Taidong xianzhi. [General Records of Taidong County.] Taidong: Taidong County government.

Kasahara, Masaharu (translated by Shufen Huang) 2009. Taiwan beinan zhu de liangge jisi. [Two Ancient Ceremonies of Puyuma Tribe in Taiwan.] Dong taiwan yanjiu [Research on Eastern Taiwan], Vol. 13, pp. 95-138.

Lin, Boxiu \& Zhu, Zimin 2009. Huadong bangqiu yu yuanzhu min. [Baseball and Aborigines in Hualian and Taidong.] Yundong wenhua yanjiu [Studies in Sports Culture], Vol. 9, pp. 67-108.

Lin, Erlang 2005. Yi daba liujiu buluo de shijian jingyan chujian beinan zu wushu de lilun. [The Fundamental Theory Construction of Wizardry in Puyuma Tribe Based on the Actual Experience in Damalakaw.] Unpublished master's thesis. Tainan: National University of Tainan.

Lin, Huawei \& Lin, Meijun 2005. Diancang Taiwan bangqiu shi: Jianong bangqiu. [The Classical Collection of Taiwanese Baseball History: Jianong Baseball Team.] Taipei: Sports Affairs Council.

Malinowski, Bronislaw 1935. Coral Gardens and their Magic: A Study of the Methods of Tilling the Soil and of Agricultural Rites in the Trobriand Islands. 2 vols. London: George Allen and Unwin.

Ministry of Interior 2010. Available at http://sowf.moi.gov.tw/stat/month/m1-08.xls, last accessed on April 18, 2013.

Qiu, Weicheng 2003. Shi suolian haishi yuyi: Yuanzhu min bangqiu xuanshou de yundong zhilu. [Chains or Wings: The Sporting Path of Aboriginal Baseball Players.] Unpublished master's thesis. Hualian: National Hualien Teachers College.

Qiu, Yunzhu 2008. Shehui jiegou yinsu yu yuanzhu min yundong xuanze zhi tantao: Yi bangqiu yundong weili. [Social Structures and Choice of Aboriginal Movements: A Study Based on Baseball Sport.] Unpublished master's thesis. Xinzhu: Yuan Ze University.

Radcliffe-Brown, Alfred 1948. The Andaman Islanders. Glencoe, IL: Free Press. 
Song, Longsheng 1965. Nanwang cun beinan zu de huisuo zhidu. [The Puyuma Youth Training System in Nanwang Village.] Kaogu renlei xuekan [Journal of Archaeology and Anthropology], Vol. 25/26, pp. 112-144.

Song, Longsheng 1998. Taiwan yuanzhu min shi: Beinan zhu shipian. [The History of Taiwanese Aborigines: The History Article of Puyuma.] Nantou: Historical Research Commission of Taiwan Province.

Sun, Minying 2001. Ma Zhili. [Ma Zhili.] In: Wang, Hesheng (ed.) Taidong xianshi: Renwu pian. [The History of Taidong County: Articles on Figures.] Taidong: Cultural Center of Taidong County, pp. 210-211.

Temporary Committee $2000=$ Temporary Investigating Committee on the Old Customs of Taiwan 2000. Fanzhu guanxi diaozha baogao shu dier juan amei zu beinan zu. [The Investigation Report on Customs and Habits of Barbarian Ethnic.] Vol. 2, Amis and Puyuma. Taipei: Institute of Ethnology Academia Sinica.

Tian, Zheyi 2002. Taiwan de yuanzhu min: Beinan zu. [Taiwanese Aborigines: Puyuma.] Taipei: Taiyuan chuban she.

Tylor, Edward Burnett 1871. Primitive Culture: Researches into the Development of Mythology, Philosophy, Religion, Art, and Custom. London: J. Murray.

Wang, Huimin 1994. Hongye de gushi. [The Story of Red Leaf.] Taipei: Minsheng bao.

Wang, Songshan 2001. Taiwan yuanzhu min de shehui yu wenhua. [Aboriginal Society and Culture in Taiwan.] Taipei: Lianjing chuban she.

Wei, Huilin 1965. Taiwan tuzhu shehui de buluo zuzhi quanwei zhidu. [The Tribal Organisation and Authoritative System in Taiwan's Indigenous Society.] Kaogu renlei xuekan [Journal of Archaeology and Anthropology], Vol. 25/26, pp. 71-87.

Xie, Shiyuan \& Xie, Jiafen 2003. Taiwan bangqiu yibai nian. [One Hundred Years of Baseball in Taiwan.] Taipei: Guoshi chuban she.

Yang, Jiangying 2003. Mukiangai: Jianhe beinan wushi de yishi shijian. [Mikiangai: The Rites and Practices of Puyuma Wizards in Jianhe.] Unpublished master's thesis. Xinzhu: National Tsing Hua University.

Yu, Junwei \& Zeng, Wencheng 2004. Taiwan bangqiu wang. [Taiwan Baseball King.] Taipei: Woshi chuban she.

Yu, Junwei 2007a. Playing in Isolation: A History of Baseball in Taiwan. Lincoln \& London: University of Nebraska Press.

Yu, Junwei 2007b. The Hongye Legend in Taiwanese Baseball: Separating Myth from Reality. The International Journal of the History of Sport, Vol. 24, No. 10, pp. 1264-1280, http://dx.doi.org/10.1080/09523360701505379.

Yu, Junwei \& Bairner, Alan 2010. Schooling Taiwan's Aboriginal Baseball Players for the Nation. Sport, Education and Society, Vol. 15, No. 1, pp. 63-82, http://dx.doi. org/10.1080/13573320903461079.

Yu, Junwei \& Tang, Shengmei \& Zeng, Wencheng \& Jia, Yizhen \& Xie, Shiyuan \& Xie, Jiafen 2006. Xuandong suiyue: Taiwan bangqiu bainian shi. [History of Baseball in Taiwan 1906-2006.] Taipei: Chinese Taipei Baseball Association.

Zeitoun, Elizabeth \& Yu, Ching-hua 2005. The Formosan Language Archive: Linguistic Analysis and Language Processing. Computational Linguistics and Chinese Language Processing, Vol. 10, No. 2, pp. 167-200. Available at http://aclweb. org/anthology-new/O/O05/O05-3002.pdf. 
Zeng, Wencheng 2001. Qishi nianqian jianong bangqiu dui de guangmang. [The Sparkling Blade of Jianong Baseball Team Seventy Years Before.] Guomin tiyu jikan [National Sports Quarterly], Vol. 30, No. 4, pp. 50-64.

Zeng, Yujuan 2009. Shengming li yu lingli de meijie wu: yu KaTatipuL beinan ren binlang wenhua weili. [The Medium of Vitality and Mana: A Case Study of Betel Nuts Culture among the Puyuma in KaTaTipuL.] Taidong: National Taidong University.

Zhang, Jingguo (ed.) 1983. Zhonghua minguo shaobang qingshao bang qingnian bangqiu fazhan shishi. [Historical Facts about Little League Baseball, Junior High School Baseball, and Senior High School Baseball in the Republic of China.] Taipei: self-published.

Zhang, Tingrong 2007. Taidong geji xuexiao bangqiu yundong fazhan zhi yanjiu (19452005). [A Study of Baseball Development at Different Levels of Schools in Taidong (1945-2005).] Unpublished master's thesis. Taidong: National Taidong University. 